\title{
Comparison of Clinical Outcome After Bypass Surgery vs. Endovascular Therapy for Infrainguinal Artery Disease in Patients With Critical Limb Ischemia
}

\author{
Yoshimitsu Soga, MD; Shinsuke Mii, MD; Hideaki Aihara, MD; Jin Okazaki, MD;
}

Sosei Kuma, MD; Terutoshi Yamaoka, MD; Daisuke Kamoi, MD; Yoshiaki Shintani, MD;

Toshinobu Ishikawa, MD on behalf of ReCANALISE Investigators

\begin{abstract}
Background: The efficacy of stent-assisted endovascular therapy (EVT) in patients with critical limb ischemia (CLI) compared to bypass surgery (BSX) remains unclear.
\end{abstract}

Methods and Results: This study was performed as a multicenter retrospective registry. Between January 2004 and December 2009, 460 CLI patients (460 first treated limbs) who underwent BSX (237 patients) or EVT (223 patients) for de novo infrainguinal lesions were identified retrospectively and analyzed. The main endpoints of this study were amputation-free survival (AFS), overall survival, limb salvage rate and freedom from major adverse limb events (MALE; includes any repeat revascularization and major amputation). Three-year AFS, limb salvage rate and overall survival were not different between the BSX and EVT groups $(60.3 \%$ vs. $58.0 \%, P=0.43 ; 85.1 \%$ vs. $84.2 \%$, $\mathrm{P}=0.91 ; 67.2 \%$ vs. $69.8 \%, \mathrm{P}=0.96$, respectively), but freedom from MALE was significantly lower in the EVT group during follow-up $(69.1 \%$ vs. $51.1 \%, P=0.002)$. After adjusting endpoints with covariates, there was also no significant difference in AFS, limb salvage, and overall survival between EVT and BSX. Freedom from MALE, however, was still significantly lower in the EVT group (hazard ratio, 0.66; 95\% confidence interval: 0.47-0.92, adjusted P=0.01).

Conclusions: Serious adverse events with the exception of MALE after EVT seem to be acceptable compared to that after BSX in patients with CLI due to infrainguinal disease. (Circ $J$ 2013; 77: 2102-2109)

Key Words: Bypass surgery; Critical limb ischemia; Endovascular therapy

$\mathbf{P}$ atients with critical limb ischemia (CLI) are treated for pain relief and improvement of ischemia, with surgical revascularization remaining as the gold standard for CLI. ${ }^{1,2}$ Recent reports, however, have suggested the efficacy of endovascular therapy (EVT) for CLI, and that the long-term outcome of this treatment is equivalent to that of surgery. ${ }^{3-6}$ The results of the landmark Bypass vs. Angioplasty in Severe Ischaemia of the Leg (BASIL) study showed that the treatment method should be selected with consideration for life expectancy and vein durability for CLI patients eligible for bypass surgery (BSX) or EVT., ${ }^{5,7}$, Surgical revascularization under general anesthesia, however, is not easy in some patients due to age, comorbidities, and general condition, and the treatment choice in actual clinical practice is still unclear.

In the BASIL study, 70\% of target lesions were femoropopliteal lesions, approximately $20 \%$ of EVT procedures were unsuccessful, and all procedures were performed with balloon angioplasty alone. ${ }^{5,9}$ These data suggest that CLI patients receiving treatment in clinical practice were underrepresented in the study. Also, the reported efficacy of a self-expandable nitinol stent for femoropopliteal lesions ${ }^{10-13}$ suggests that further examination of the treatment choice is needed, with consideration of background factors. Here, we report the outcomes of patients who received BSX or stent-assisted EVT for de novo infrainguinal lesions.

\section{Method}

\section{Subjects}

The study was performed as a multicenter retrospective registry in Japan enrolling consecutive patients undergoing first BSX or EVT between January 2004 and December 2009. Of 1,508

Received January 8, 2013; revised manuscript received February 20, 2013; accepted March 22, 2013; released online April 26, 2013 Time for primary review: 20 days

Department of Cardiology (Y. Soga, H.A.), Department of Vascular Surgery (J.O., S.K.), Kokura Memorial Hospital, Kitakyushu; Department of Vascular Surgery, Seitetsu Memorial Yahata Hospital, Kitakyushu (S.M.); Department of Surgery, Matsuyama Red Cross Hospital, Matsuyama (T.Y.); Department of Cardiology, Nagoya Kyoritsu Hospital, Nagoya (D.K.); Department of Cardiology, ShinKoga Hospital, Kurume (Y. Shintani); and Department of Cardiology, Oita Oka Hospital, Oita (T.I.), Japan

Mailing address: Yoshimitsu Soga, MD, Department of Cardiology, Kokura Memorial Hospital, 3-2-1 Asano, Kokurakita-ku, Kitakyushu 802-0001, Japan. E-mail: sogacchy@yahoo.co.jp

ISSN-1346-9843 doi:10.1253/circj.CJ-13-0020

All rights are reserved to the Japanese Circulation Society. For permissions, please e-mail: cj@j-circ.or.jp 


\section{Participant Flow}

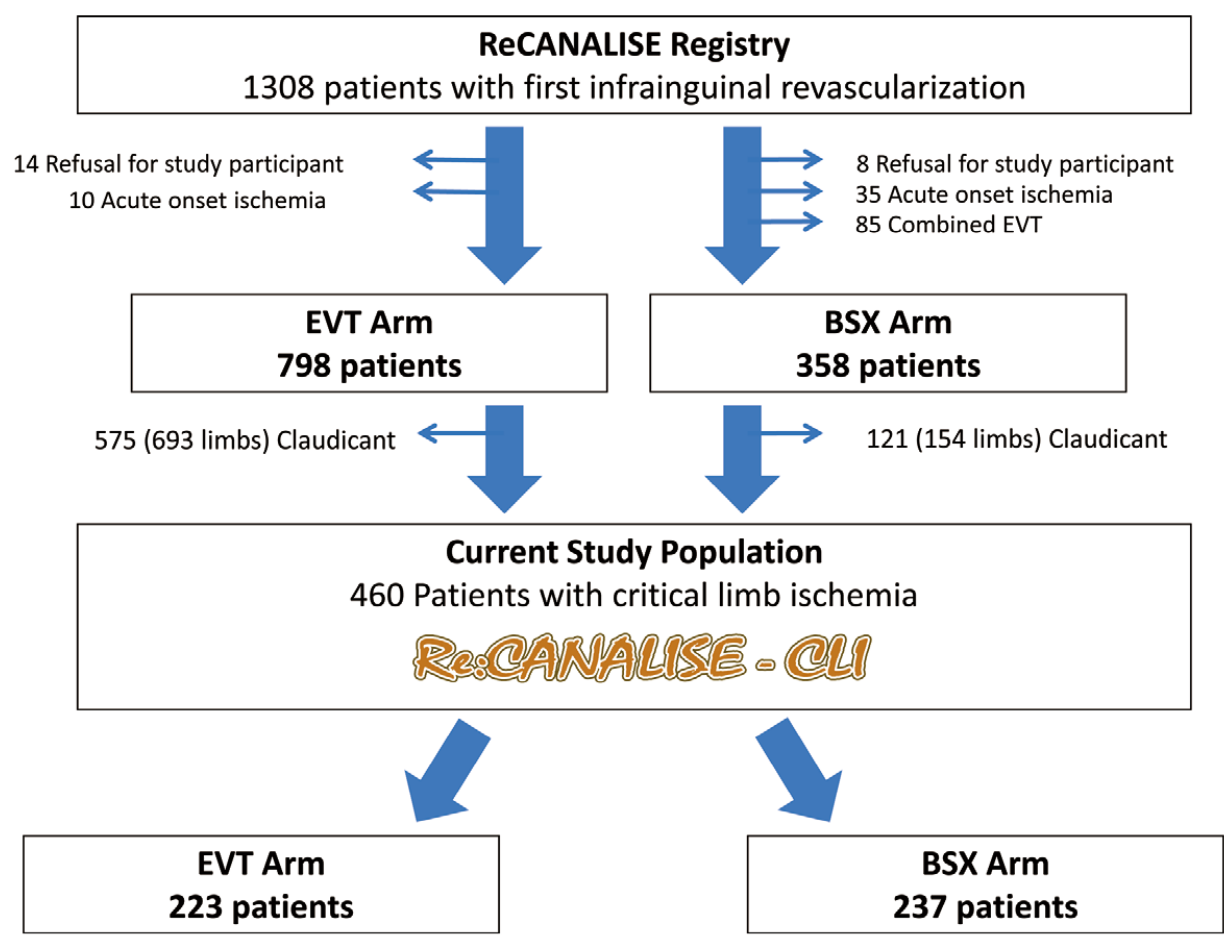

Figure 1. Participant flow. BSX, bypass surgery; CLI, critical limb ischemia; EVT, endovascular therapy.

patients enrolled in this registry, the subject group for the prespecified subanalysis of the ReCANALISE Registry consisted of 460 patients with CLI (237 patients received BSX and 223 patients received EVT) excluding those patients who refused study participation and had acute onset limb ischemia (Figure 1).

Baseline demographic, angiographic and procedural data were collected from each hospital database according to prespecified definitions by independent researchers. Collection of follow-up data was conducted through review of inpatient and outpatient hospital charts, contact with patients, relatives, and/ or referring physicians. Death and major amputation were adjudicated by the clinical event committee. The mean follow-up interval of the 300 survivors was 1,058 days (interquartile range, 717-1,415 days). Complete 1-year follow-up information was achieved in $94.1 \%$ of patients $(95.8 \%$ in the BSX group and $92.4 \%$ in the EVT group; $\mathrm{P}=0.12$ ).

\section{Procedure}

EVT was performed as a provisional stent strategy for femoropopliteal lesion. Balloon angioplasty was performed with an optimally size. If the result was suboptimal, a stent was implanted. Two types of nitinol stents were implanted: Luminexx (Bard, Murray Hill, NJ, USA) and S.M.A.R.T. (Cordis J\&J, Miami, FL, USA). The stent type was determined by the operators. For infrapopliteal lesions, balloon angioplasty was performed with optimally sized balloon, repeatedly. After the procedure, all patients were prescribed lifelong aspirin. At the operator's discretion, thienopyridines and/or cilostazol were added.

Surgical revascularization was performed with the use of standard bypass techniques. Whenever possible, the vein bypass graft was used. Post-procedural medication was selected according to local clinical practice.

\section{Outcome Measures}

The primary outcome measure was amputation-free survival (AFS), and the secondary outcome measures were overall survival, limb salvage rate, freedom from major adverse limb events (MALE; includes any repeat revascularization [any endovascular procedure, any surgical revision and use of thrombectomy or thrombolysis] and major amputation), major adverse cardiovascular events (MACE; includes all-cause death, non-fatal myocardial infarction [MI] and stroke) and major adverse cardiovascular and limb events (MACLE; MACE+ MALE).

\section{Definitions}

Limb salvage was defined as freedom from major amputation, which was defined as amputation above the ankle. In patients with tissue loss, wound healing was defined by the achievement of complete epithelialization of all wounds in their affected limbs. The time from the initial revascularization to complete epithelialization was defined as healing time. The presence of wound healing was diagnosed at the follow-up visit. Coronary artery disease (CAD) was defined as stable angina with documented CAD, history of percutaneous coronary intervention or coronary artery bypass graft surgery, or previous 


\begin{tabular}{|c|c|c|c|}
\hline Characteristics & BSX $(n=237)$ & EVT $(n=223)$ & P-value \\
\hline Age (years) & $72 \pm 9$ & $71 \pm 11$ & 0.53 \\
\hline$>75$ years & $101(43)$ & $84(38)$ & 0.28 \\
\hline Female & $70(30)$ & $85(38)$ & 0.05 \\
\hline BMI $\left(\mathrm{kg} / \mathrm{m}^{2}\right)$ & $21 \pm 3$ & $21 \pm 3$ & 0.40 \\
\hline$<18$ & $37(16)$ & $38(17)$ & 0.68 \\
\hline$>25$ & $23(10)$ & $18(8)$ & 0.54 \\
\hline Ambulatory & $154(65)$ & $119(53)$ & 0.01 \\
\hline Hypertension & $186(78)$ & $167(75)$ & 0.36 \\
\hline Hyperlipidemia & $55(23)$ & $65(29)$ & 0.15 \\
\hline Diabetes & $147(62)$ & $144(65)$ & 0.57 \\
\hline Hemodialysis & $85(36)$ & $124(56)$ & $<0.0001$ \\
\hline Current smoker & $60(25)$ & $43(19)$ & 0.12 \\
\hline Previous smoker & $99(43)$ & $334(41)$ & 0.50 \\
\hline Cerebrovascular disease & $88(38)$ & $166(32)$ & 0.09 \\
\hline CAD & $106(45)$ & $143(64)$ & $<0.0001$ \\
\hline COPD & $23(10)$ & $57(7)$ & 0.12 \\
\hline Atrial fibrillation & $31(13)$ & $34(15)$ & 0.50 \\
\hline Heart Failure & $38(16)$ & $79(35)$ & $<0.0001$ \\
\hline LV dysfunction $^{\dagger}$ & $18(8)$ & $32(14)$ & 0.02 \\
\hline \multicolumn{4}{|l|}{ Rutherford class } \\
\hline IV/V/VI & $52 / 145 / 40$ & $70 / 120 / 33$ & 0.07 \\
\hline Tissue loss & $179(78)$ & $154(69)$ & 0.03 \\
\hline CLI in other leg & $37(16)$ & $44(20)$ & 0.25 \\
\hline $\mathrm{HbA1c}$ & $6.6 \pm 1.8$ & $6.4 \pm 1.5$ & 0.34 \\
\hline Serum albumin (g/dl) & $3.6 \pm 0.5$ & $3.3 \pm 0.5$ & $<0.0001$ \\
\hline Albumin $<3.0 \mathrm{~g} / \mathrm{dl}$ & $28(12)$ & $53(24)$ & 0.0008 \\
\hline Hemoglobin (g/dl) & $11 \pm 2$ & $11 \pm 2$ & 0.47 \\
\hline Anemia $\ddagger$ & $109(46)$ & $98(44)$ & 0.66 \\
\hline CRP (mg/dl) & $2.3 \pm 3.4$ & $1.7 \pm 2.6$ & 0.03 \\
\hline $\mathrm{CRP}>3 \mathrm{mg} / \mathrm{dl}$ & $60(25)$ & $36(16)$ & 0.02 \\
\hline Pre-procedural ABI & $0.39 \pm 0.32$ & $0.49 \pm 0.32$ & 0.002 \\
\hline Post-procedural ABI & $0.89 \pm 0.27$ & $0.80 \pm 0.26$ & 0.001 \\
\hline Initial hospital stay (days) & $57 \pm 52$ & $16 \pm 25$ & $<0.0001$ \\
\hline \multicolumn{4}{|l|}{ Medication } \\
\hline Aspirin & $136(57)$ & $187(84)$ & $<0.001$ \\
\hline Thienopyridines & $43(18)$ & $110(49)$ & $<0.0001$ \\
\hline Cilostazol & $69(29)$ & $92(41)$ & 0.006 \\
\hline Sarpogrelate & $36(15)$ & $23(10)$ & 0.12 \\
\hline Beraprost & $46(19)$ & $38(17)$ & 0.51 \\
\hline Statins & $53(22)$ & $110(49)$ & $<0.0001$ \\
\hline Eicosapentaenoic acid & $54(23)$ & $13(6)$ & $<0.0001$ \\
\hline Warfarin & $58(24)$ & $14(6)$ & $<0.0001$ \\
\hline ACEI/ARB & $107(45)$ & $125(56)$ & 0.02 \\
\hline Calcium antagonist & $137(58)$ & $173(78)$ & $<0.0001$ \\
\hline$\beta$-blockade & $43(18)$ & $44(20)$ & 0.66 \\
\hline H2-blocker & $45(19)$ & $32(14)$ & 0.18 \\
\hline Proton pump inhibitor & $72(30)$ & $74(33)$ & 0.52 \\
\hline
\end{tabular}

Data given as mean \pm SD or $n(\%)$. ${ }^{+}$Defined as $<40 \%$ of LV ejection fraction; $¥$ defined as $<11 \mathrm{~g} / \mathrm{dl}$ hemoglobin. $A B I$, ankle-brachial index; BSX, bypass surgery; BTK, below the knee; BMI, body mass index; CAD, coronary artery disease; $\mathrm{CLI}$, critical limb ischemia; COPD, chronic obstructive pulmonary disease; CRP, C-reactive protein; EVT, endovascular therapy; FP, femoropopliteal; LV, left ventricular.

MI. Cerebrovascular disease was defined as hospital or neurologist diagnosis of transient ischemic attack or ischemic stroke. Heart failure (HF) was defined as previous diagnosis of HF, history of hospitalization for HF, or current treatment for HF. Left ventricular (LV) dysfunction was defined as $<40 \%$ of $\mathrm{LV}$ ejection fraction Diabetes was defined as $\mathrm{HbA}_{1 \mathrm{c}}>6.5 \%$, casual plasma glucose $>200 \mathrm{mg} / \mathrm{dl}$ or treatment with oral hypoglycemic agents or insulin injection. Hypertension was defined as systolic blood pressure $\geq 140 \mathrm{mmHg}$ and/or diastolic blood pressure $\geq 90 \mathrm{mmHg}$ or ongoing therapy for hypertension. 


\begin{tabular}{|c|c|c|c|}
\hline Characteristics & BSX $(n=237)$ & EVT $(n=223)$ & P-value \\
\hline \multicolumn{4}{|l|}{ Treated lesion } \\
\hline Femoropopliteal & $107(45)$ & $94(42)$ & \\
\hline Infrapopliteal & $54(23)$ & $51(23)$ & 0.77 \\
\hline Both & $76(32)$ & $78(35)$ & \\
\hline \multicolumn{4}{|l|}{ Femoropopliteal } \\
\hline No. treated lesions & 183 & 172 & \\
\hline TASCII2 A/B/C/D & $14 / 35 / 17 / 117$ & $28 / 58 / 47 / 39$ & $<0.0001$ \\
\hline Lesion length (mm) & $169 \pm 78$ & $114 \pm 79$ & $<0.0001$ \\
\hline Reference vessel diameter $(\mathrm{mm})$ & $5.5 \pm 1.0$ & $5.1 \pm 1.1$ & 0.003 \\
\hline Pre-procedure \% stenosis & $97 \pm 8$ & $92 \pm 10$ & $<0.0001$ \\
\hline Post-procedure \% stenosis & - & $17 \pm 18$ & \\
\hline Calcified lesion§ & $56(31)$ & $129(75)$ & $<0.0001$ \\
\hline Chronic total occlusion & $141(77)$ & $111(66)$ & 0.009 \\
\hline \multicolumn{4}{|l|}{ Infrapopliteal } \\
\hline No. treated lesions & 130 & 129 & \\
\hline $\mathrm{TASC}^{14} \mathrm{~A} / \mathrm{B} / \mathrm{C} / \mathrm{D}$ & $1 / 1 / 2 / 126$ & $5 / 15 / 17 / 92$ & $<0.0001$ \\
\hline Lesion length (mm) & $187 \pm 48$ & $153 \pm 76$ & $<0.0001$ \\
\hline Reference vessel diameter $(\mathrm{mm})$ & $2.5 \pm 0.4$ & $2.3 \pm 0.6$ & 0.0009 \\
\hline Pre-procedure \% stenosis & $98 \pm 11$ & $98 \pm 6$ & 0.49 \\
\hline Post-procedure \% stenosis & - & $28 \pm 12$ & \\
\hline Calcified lesion§ & $82(63)$ & $206(82)$ & 0.0004 \\
\hline Chronic total occlusion & $125(96)$ & $86(67)$ & $<0.0001$ \\
\hline Poor run-off & $220(93)$ & $215(96)$ & 0.09 \\
\hline \multicolumn{4}{|l|}{ Procedure } \\
\hline Femoropopliteal bypass & $100(42)$ & - & \\
\hline ATK/BTK & $80 / 20$ & - & \\
\hline Distal bypass & $137(58)$ & - & \\
\hline Use of autogenous vein graft & $166(70)$ & - & \\
\hline Femoropopliteal stenting & - & $101 / 172(60)$ & \\
\hline SMART/Luminexx & - & $84 / 17$ & \\
\hline Stent fracture & - & $8(4)$ & \\
\hline Use of contrast media (ml) & - & $131 \pm 72$ & \\
\hline Operation/procedure time ( $\mathrm{min})$ & $289 \pm 114$ & $78 \pm 33$ & $<0.0001$ \\
\hline
\end{tabular}

Data given as mean $\pm \mathrm{SD}$ or $\mathrm{n}(\%)$. \$Defined as obvious densities noted within the apparent vascular wall in the angiogram. ATK, above the knee; TASC, TransAtlantic Inter-Society consensus. Other abbreviations as in Table 1.

Hyperlipidemia was defined as total cholesterol $>220 \mathrm{mg} / \mathrm{dl}$ or triglyceride $>150 \mathrm{mg} / \mathrm{dl}$ or treatment with any lipid-lowering agents. Non-ambulatory status was regarded as wheelchair use or being bedridden. Emaciation was defined as body mass index $(\mathrm{BMI})<18$. Elderly was defined as $>75$ years of age.

\section{Statistical Analysis}

Data are reported as mean $\pm \mathrm{SD}$. Continuous variables were examined using unpaired t-test or Mann-Whitney U-test. Categorical variables were compared by chi-square or Fisher's exact test. Survival or event-free curves were estimated using the Kaplan-Meier method and compared with the log-rank test. To determine the predictors for each outcome in this study, log-rank test was conducted for the following clinically potential variables: elderly ( $>75$ years), gender, emaciation (BMI $<18$ ), overweight (BMI >25), hypertension, hyperlipidemia, diabetes, non-ambulation, hemodialysis, current or previous smoker, CAD, cerebrovascular disease, chronic obstructive pulmonary disease, HF, LV dysfunction, anemia (hemoglobin $<11 \mathrm{~g} / \mathrm{dl}$ ), albumin $<3.0 \mathrm{~g} / \mathrm{dl}$, C-reactive protein $>3.0 \mathrm{mg} / \mathrm{dl}$, preand post-procedural ankle-brachial index, tissue loss, bilateral
CLI, calcified lesion, isolated infrapopliteal lesion and use of medications such as statins, aspirin, thienopyridines, cilostazol, warfarin, angiotensin-converting enzyme inhibitor (ACEI)/angiotensin receptor blocker (ARB), calcium antagonist, betablockade, H2-blocker and proton pomp inhibitor. The assumption of the proportional hazard was verified by a visual estimate of the $\log$ (minus log) curves. Those variables with $\mathrm{P}<0.05$ on univariate analysis and for which proportional assumptions were generally fair were included in multivariate analysis. Obtained predictors were used as covariates for adjustment in each outcome. $\mathrm{P}<0.05$ was considered statistically significant.

\section{Results}

Baseline Characteristics

Baseline patient characteristics are listed in Table 1. Prevalence of dialysis, CAD, HF and LV dysfunction was greater in the EVT group, while the BSX group included more ambulatory patients. Hospital stay and procedure time were longer in the BSX group. The EVT group generally included more high- 
A Amputation-free survival

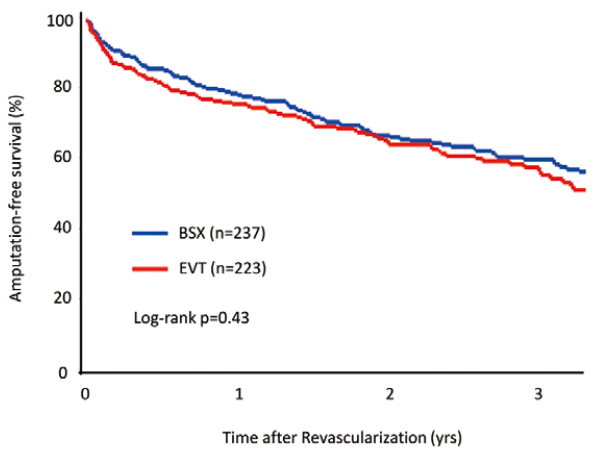

B Limb Salvage Rate

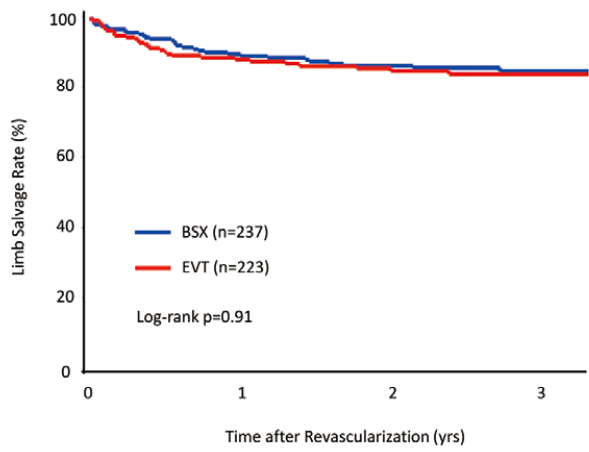

C Overall Survival

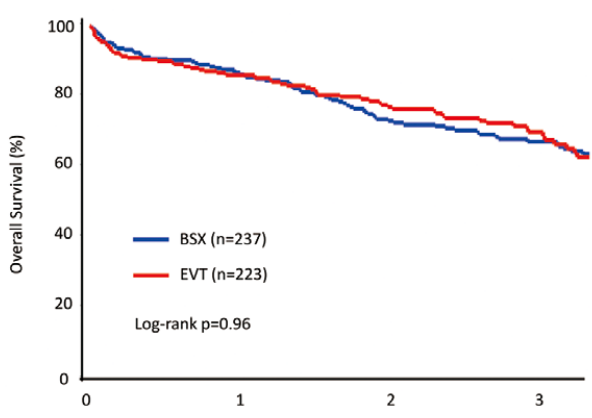

Time after Revascularization (yrs)

\begin{tabular}{lcccccc}
\hline & & $\mathbf{0}$ days & $\mathbf{3 0}$ days & $\mathbf{1}$ year & $\mathbf{2 \text { years }}$ & $\mathbf{3 \text { years }}$ \\
\hline \multirow{2}{*}{ Bypass Surgery } & No. at risk & 237 & 229 & 196 & 144 & 100 \\
& $\mathbf{x}$ & 100 & 96.6 & 86.7 & 73.0 & 67.2 \\
Endovascular therapy & No. at risk & 223 & 213 & 173 & 132 & 80 \\
& $\mathbf{X}$ & 100 & 95.5 & 86.1 & 76.9 & 69.8 \\
\hline
\end{tabular}

E Freedom from MACE

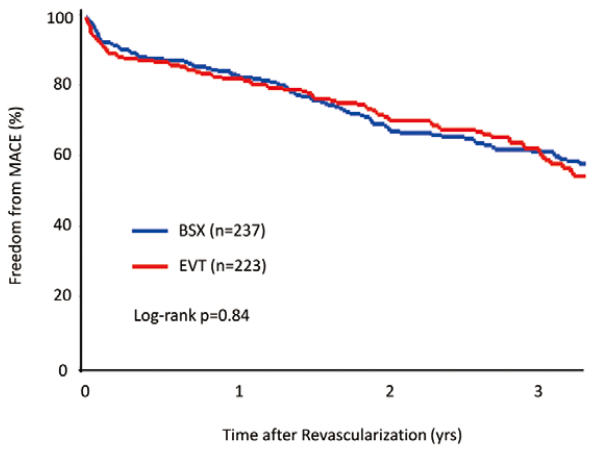

\begin{tabular}{lcccccc}
\hline & & 0 days & $\mathbf{3 0}$ days & $\mathbf{1}$ year & $\mathbf{2}$ years & $\mathbf{3}$ years \\
\hline Bypass Surgery & No. at risk & 237 & 224 & 189 & 137 & 95 \\
& $\mathbf{6}$ & 100 & 94.5 & 83.7 & 69.1 & 61.8 \\
Endovascular therapy & No. a trisk & 223 & 208 & 166 & 124 & 75 \\
& $\mathbf{6}$ & 100 & 93.3 & $\mathbf{8 2 . 5}$ & 71.7 & 62.7 \\
\hline
\end{tabular}

D Freedom from MALE

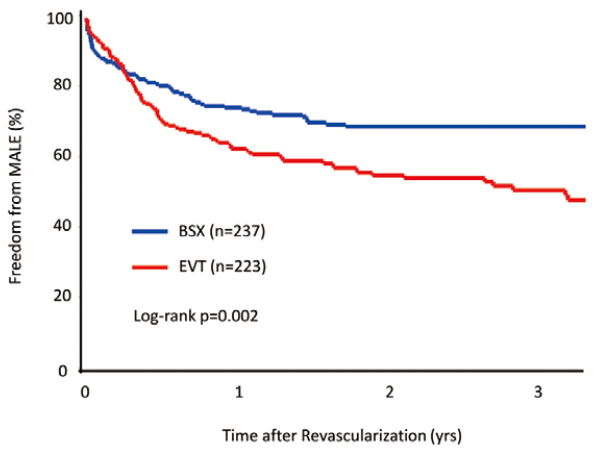

\begin{tabular}{lcccccc}
\hline & & $\mathbf{0}$ days & 30 days & 1 year & 2 years & 3 years \\
\hline Bypass Surgery & No. at risk & 237 & 205 & 150 & 110 & 77 \\
& $\mathbf{6}$ & 100 & 89.4 & 74.5 & 69.1 & 69.1 \\
Endovascular therapy & No. at risk & 223 & 198 & 113 & 74 & 39 \\
& $\mathbf{x}$ & 100 & 93.2 & 62.9 & 55.3 & 51.1
\end{tabular}

F Freedom from MACLE

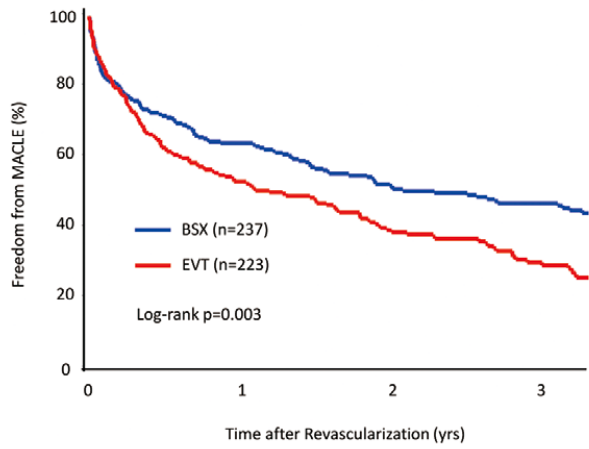

\begin{tabular}{lcccccc}
\hline & & 0 days & 30 days & 1 year & 2 vears & 3 vears \\
\hline \multirow{2}{*}{ Bypass Surgery } & No. at risk & 237 & 200 & 145 & 106 & 74 \\
& $\mathbf{6}$ & 100 & 84.4 & 63.9 & 52.3 & 46.9 \\
Endovascular therapy & No. at risk & 223 & 193 & 109 & 70 & 36 \\
& $\mathbf{6}$ & 100 & 86.5 & 53.0 & 39.2 & 30.1
\end{tabular}

Figure 2. (A) Amputation-free survival; (B) limb salvage rate; (C) overall survival; (D) freedom from major adverse limb events (MALE; defined as any repeat revascularization [includes any endovascular procedure, any surgical revision and use of thrombectomy or thrombolysis] and major amputation); (E) freedom from major adverse cardiovascular events (MACE; defined as allcause death, non-fatal myocardial infarction and stroke); (F) freedom from major adverse cardiovascular and limb events (MACLE; defined as MALE + MACE). 


\begin{tabular}{|c|c|c|c|c|c|c|}
\hline Outcome & $\begin{array}{c}\text { BSX, } \\
n=237(\%)\end{array}$ & $\begin{array}{c}\text { EVT, } \\
\mathrm{n}=223(\%)\end{array}$ & $\begin{array}{l}\text { Unadjusted HR } \\
\quad(95 \% \mathrm{Cl})\end{array}$ & P-value & $\begin{array}{c}\text { Adjusted HR } \\
(95 \% \mathrm{CI})\end{array}$ & P-value \\
\hline \multicolumn{7}{|l|}{ Primary endpoint } \\
\hline AFS & $106(45)$ & $96(43)$ & $0.89(0.68-1.18)$ & 0.85 & $1.01^{*}(0.75-1.36)$ & 0.94 \\
\hline \multicolumn{7}{|c|}{ Secondary endpoints } \\
\hline Limb salvage & $33(14)$ & $28(13)$ & $1.28(0.85-1.92)$ & 0.24 & $1.19^{\dagger}(0.71-2.00)$ & 0.51 \\
\hline Overall survival & $88(37)$ & $72(32)$ & $0.90(0.70-1.15)$ & 0.40 & $1.28^{\ddagger}(0.91-1.78)$ & 0.16 \\
\hline MALE & $71(30)$ & $94(42)$ & $0.73(0.56-0.95)$ & 0.02 & $0.66^{* \star}(0.47-0.92)$ & 0.01 \\
\hline MACE & $102(43)$ & $87(39)$ & $0.97(0.73-1.30)$ & 0.84 & $1.19^{\star \star \star}(0.87-1.62)$ & 0.28 \\
\hline MACLE & $141(59)$ & $154(69)$ & $0.71(0.56-0.89)$ & 0.003 & $0.75^{\star \star \star \star}(0.58-0.97)$ & 0.02 \\
\hline
\end{tabular}

Unadjusted and adjusted risks of bypass surgery compared to endovascular therapy for the outcome measures were evaluated. Adjusted by covariates with significant multivariate impact on investigated outcome measures: *emaciation, ambulatory, tissue loss, dialysis, LV dysfunction, warfarin and statins; †ambulatory, tissue loss and cilostazol; ‘emaciation, ambulatory, tissue loss, dialysis, chronic obstructive pulmonary disease, LV dysfunction, warfarin and statins; Semaciation, ambulatory, tissue loss, hyperlipidemia, LV dysfunction and thienopyridines; ${ }^{* *}$ tissue loss, dialysis and warfarin; ${ }^{* * *}$ elderly, hypoalbuminemia, dialysis, atrial fibrillation, LV dysfunction and ACEI/ARB; ${ }^{* \star \star *}$ emaciation, hypoalbuminemia, CRP $>3.0 \mathrm{mg} / \mathrm{dl}$, dialysis, atrial fibrillation, LV dysfunction and cilostaol.

AFS, amputation-free survival; Cl, confidence interval; CV, cardiovascular; EVT, endovascular therapy; HR, hazard ratio; MACE, major adverse cardiovascular events (include all-cause death; non-fatal myocardial infarction or stroke); MACLE, major adverse cardiovascular and limb events (MACE + MALE); MALE, major adverse limb events (include any repeat revascularization or major amputation). Other abbreviations as in Table 1.

risk patients, such as those with dialysis, diabetes, CAD, and $\mathrm{HF}$, as well as elderly and non-ambulatory patients.

The lesion and procedural characteristics are given in Table 2. Femoropopliteal lesions alone were treated in 201 patients (43.7\%), isolated infrapopliteal lesions in 105 (22.8\%), and both lesions in 154 (33.5\%). Bilateral CLI was observed in 81 patients $(17.6 \%)$. Treated femoropopliteal and infrapopliteal lesion was longer, and vessel diameter was larger in the BSX group than in the EVT group. Patients who received BSX were more likely to have total occlusion and less likely to have calcified lesion.

In the BSX group, autogenous vein graft was used in $70 \%$ of patients (166/237), but all distal bypass surgery was performed with autogenous vein graft. In the EVT group, selfexpandable nitinol stent was used in $60 \%$ of patients $(101 / 172)$ who received EVT for femoropopliteal lesion. Balloon angioplasty was used in all procedures for infrapopliteal lesion, except in 1 patient, who received coronary bare-metal stenting for bailout. Regarding medications, statins, aspirin, thienopyridines, cilostazol, statin, ACEI/ARB and calcium antagonist were more frequently used and warfarin and eicosapentaenoic acid was less frequently used in the EVT group than in the BSX group.

\section{Primary and Secondary Outcome Measures}

In the total patient group, AFS outcome was not different between the BSX and EVT groups (60.3\% vs. $58.0 \%$ at 3 years, log-rank $\mathrm{P}=0.43$; Figure $2 \mathrm{~A}$ ). Limb salvage rate and overall survival were also similar $(85.1 \%$ vs. $84.2 \%$ at 3 years, logrank $\mathrm{P}=0.91$; Figure $2 \mathrm{~B} ; 67.2 \%$ vs. $69.8 \%$ at 3 years, log-rank $\mathrm{P}=0.96$; Figure 2C, respectively). There was no significant difference in 30-day mortality between the groups $(3.8 \%$ vs. $4.5 \%, \mathrm{P}=0.71)$. Freedom from MALE was significantly lower in the EVT group during the follow-up $(69.1 \%$ vs. $51.1 \%$ at 3 years, log-rank $\mathrm{P}=0.002$; Figure 2D). Freedom from MACE did not significantly differ between BSX and EVT groups ( $61.8 \%$ vs. $62.7 \%$ at 3 years, log-rank $\mathrm{P}=0.84$; Figure $2 \mathrm{E}$ ). Freedom from MACLE (MACE+MALE) was significantly higher in the BSX group ( $46.9 \%$ vs. $30.1 \%$ at 3 years, log-rank $\mathrm{P}=0.003$; Figure 2F).

After correcting all endpoints with covariates (Table 3), there was no significant difference in AFS (adjusted hazard ratio
[HR], 1.01; 95\% confidence interval [CI]: 0.75-1.36, P=0.94). Also, no significant difference was found in limb salvage (adjusted HR, 1.19; 95\% CI: 0.71-2.00, $\mathrm{P}=0.51$ ) and overall survival (adjusted HR, 1.28; 95\% CI: 0.91-1.78, $\mathrm{P}=0.16$ ) between EVT and BSX. Among 160 patients who died during followup, the cause of death was cardiac in 77 (48\%), non-cardiac vascular in $16(10 \%)$, and non-cardiovascular in $67(42 \%)$. There is no significant difference of cardiac and cardiovascular death between BSX and EVT (50\% vs. 46\%, $\mathrm{P}=0.60$; and $60 \%$ vs. $56 \%, \mathrm{P}=0.55$, respectively). Freedom from MALE, however, was significantly lower in the EVT group (adjusted HR, 0.66; 95\% CI: 0.47-0.92, $\mathrm{P}=0.01$ ). Although freedom from MACE was similar in both groups (adjusted HR, 1.19; $95 \%$ CI: 0.87-1.62, $\mathrm{P}=0.28$ ), freedom from MACLE (MACE+ MALE) was significantly lower in the EVT group (adjusted HR, 0.75; 95\% CI: 0.58-0.97, P=0.02). EVT was significantly related with the incidence of MALE.

\section{Discussion}

In this study, we examined the efficacy of BSX and EVT in clinical practice. A vein bypass graft was used for most BSX procedures, while provisional stenting was used for femoropopliteal lesions in EVT. The EVT group included many patients who were on hemodialysis and non-ambulatory, or had $\mathrm{CAD}, \mathrm{HF}$ and LV dysfunction. Thus, EVT was selected due to poor general conditions and a high risk for general anesthesia. In contrast, BSX was selected for tissue loss in patients with relatively favorable general conditions and diffuse lesions over the entire lower extremities, including obstruction. Compared to the BASIL study, the present patients had a more complicated background, because many of these patients were elderly and had diabetes, hemodialysis, or had an isolated infrapopliteal lesion.

In the guidelines prepared based on the results of the BASIL study, BSX should be selected for patients with life expectancy of 2 years or longer and a durable vein. ${ }^{7,8,15}$ In the current study, elderly age (HR, 1.72; 95\% CI: 1.23-2.41, $\mathrm{P}=0.002)$, albumin $<3.0 \mathrm{~g} / \mathrm{dl}$ (HR, 1.70; 95\% CI: $1.13-2.57, \mathrm{P}=0.01)$, hemodialysis (HR, 1.47; 95\% CI: $1.05-2.05, \mathrm{P}<0.0001$ ), atrial fibrillation (HR, 1.70; 95\% CI: 1.14-2.54, P=0.009), LV dys- 
function (HR, 2.25; 95\% CI: 1.44-3.51, $\mathrm{P}=0.0004)$, and ACEI/ ARB (HR, 0.62; 95\% CI: 0.45-0.86, P=0.004) were identified as independent predictors for all-cause mortality. An EVTfirst strategy should be considered from the perspective of prognosis for patients with several risk factors related to total mortality. In addition, Azuma et al found that artificial dialysis, diabetes, hypoalbuminemia (defined as serum albumin $<3.0 \mathrm{~g} / \mathrm{dl}$ ), heel ulcer/gangrene, and R6 except heel were independent predictors for major amputation before wound cure or death in CLI patients who received BSX.16 AFS measured 2 years after BSX was particularly low (approximately 30\%) in dialysis patients with hypoalbuminemia. Thus, EVT or primary amputation should be considered as first-line treatment for patients with a poor survival prognosis and for those in whom improvement of the wound is unlikely.

Regarding wound management after surgical or endovascular revascularization in the present study, it was of note that the vascular surgeon at the facility where the surgery was performed was continuously engaged in wound management in patients treated with BSX (total management from revascularization to wound treatment). In contrast, in most EVT cases, plastic surgeons or vascular surgeons at the facility where revascularization was performed were involved in wound management in cooperation with doctors at nearby hospitals (separate management of revascularization and wound treatment). This suggests that an effect equivalent to that of BSX may be obtained by forming a multidisciplinary team including experts in wound treatment and rehabilitation after successful revascularization in cases in which the goal of EVT is radical cure in CLI patients (especially those with tissue loss) treated at specialized facilities for intervention.

The incidence of repeat revascularization in the EVT-first group was significantly higher than that in the BSX-first group, but the surgical conversion in the EVT-first group was $13.9 \%$ $(31 / 223)$ during the observation period, which was similar to the rate of surgical revision $(12.7 \%)$ in the BSX-first group $(\mathrm{P}=0.69)$. In the BASIL study, the rate of surgical conversion in the angioplasty group was $22 \%$, which was higher than that in the current study. The lower rate of surgical conversion in the present study occurred because the stent was used for bailout and EVT was selected for repeat revascularization. In addition, in the BASIL study, the outcome of AFS in BSX after failed EVT was poorer than that in initial BSX. ${ }^{9}$ In the current study, the AFS rate in 23 subjects who received BSX after failed EVT was $69.6 \%$ and $56.5 \%$ after 1 and 3 years, respectively, showing no significant difference to that of the 237 subjects in the BSX-first group ( $\mathrm{P}=0.69, \log$-rank test) and of the 200 subjects in the successful EVT group ( $\mathrm{P}=0.91$, logrank test). And failed EVT was not an adverse prognostic factor for AFS (HR, 1.10; 95\% CI: 0.56-2.15, P=0.78). The limb salvage rate in the BSX group after failed or inadequate EVT was $90.2 \%$ and $90.2 \%$ after 1 and 3 years, respectively, showing no significant difference to the BSX-first group $(\mathrm{P}=0.67$, log-rank test) and successful EVT group $(\mathrm{P}=0.53$, log-rank test). Also, failed EVT was not a predictor of limb salvage (HR, 0.69; 95\% CI: 0.17-2.80, $\mathrm{P}=0.60$ ). This may have been because the period to bypass conversion was short (median, 42 days; interquartile range, 3-123 days). In half of the patients, BSX was performed within 3 weeks after failed EVT. Swift judgment may contribute to acceptable outcome.

The initial procedure time in the EVT-first group was shorter than that in the BSX-first group (78 \pm 33 min vs. $289 \pm 114 \mathrm{~min}$, $\mathrm{P}<0.0001$; Table 2) and the initial hospitalization period was also significantly shorter $(16 \pm 25$ days vs. $57 \pm 52$ days, $\mathrm{P}<0.0001$; Table 1). Medical costs were not examined in the present study.
In the BASIL study the initial cost in the BSX group was high, but the cost in the EVT group increased when the observation period was extended. ${ }^{17}$ Many patients in the EVT group were readmitted to hospital for repeat revascularization and this might be 1 of the reasons for the increased cost in the late phase. In recent years, drug-eluting stents and drug-coated balloons for infrainguinal lesion have been shown to have preventive effects against restenosis. ${ }^{18-22}$ Such development of new devices may contribute to a decrease in the cost for rehospitalization and repeat revascularization. Therefore, future comparisons of strategies such as conventional therapy and EVT with new devices will need to evaluate therapeutic results and medical costs over the entire observation period.

\section{Study Limitations}

There were several limitations to the present study. First, we used a retrospective analysis, despite this being a multicenter study. Second, although the adjusted factors were prespecified and seemed clinically reasonable, these variables were arbitrary. Third, the study was performed in Japanese patients and it is unclear whether similar results would be obtained in other races with different muscle amounts and physical size. In addition, cultural, social or economic factors may be important. Finally, the present conclusions might not be applicable to patients with anatomic complexities such as diffuse lesion or vessel run-off, which were not evaluated in this study. Variations, however, in the frequencies of anatomic factors such as calcified lesions and the presence of total occlusions were adjusted for in comparative analysis. Furthermore, important medications, such as statins or antiplatelet agents, for prevention of cardiovascular events were apparently underused. Greater use of these therapies might have affected the long-term outcomes of both BSX and EVT.

\section{Conclusion}

Clinical outcomes such as AFS, limb salvage and overall survival were similar for EVT or BSX as first revascularization in real-world practice for CLI patients with infrainguinal artery disease. The frequency of MALE, however, especially repeat revascularization, was significantly greater in the EVT group compared to the BSX group. This suggests that serious adverse events after EVT-first revascularization seemed to be acceptable compared to that after BSX in patients with CLI due to infrainguinal disease. The higher incidence of MALE in CLI patients who received EVT is a future consideration.

\section{Disclosures}

Financial Support: None. Conflict of Interest: None declared.

\section{References}

1. Pomposelli FB, Kansal N, Hamdan AD, Belfield A, Sheahan M, Campbell DR, et al. A decade of experience with dorsalis pedis artery bypass: Analysis of outcome in more than 1000 cases. J Vasc Surg 2003; 37: 307-315.

2. Norgren L, Hiatt WR, Dormandy JA, Nehler MR, Harris KA, Fowkes $\mathrm{FG}$, et al. Inter-Society consensus for the management of peripheral arterial disease (TASC II). Eur J Vasc Endovasc Surg 2007; 33(Suppl 1): $\mathrm{S} 1-\mathrm{S} 75$

3. Söderström MI, Arvela EM, Korhonen M, Halmesmäki KH, Albäck AN, Biancari F, et al. Infrapopliteal percutaneous transluminal angioplasty versus bypass surgery as first-line strategies in critical leg ischemia: A propensity score analysis. Ann Surg 2010; 252: $765-$ 773.

4. Casella IB, Brochado-Neto FC, Sandri Gde A, Kalaf MJ, Godoy MR, Costa VS, et al. Outcome analysis of infrapopliteal percutaneous transluminal angioplasty and bypass graft surgery with nonreversed sa- 
phenous vein for individuals with critical limb ischemia. Vasc Endovasc Surg 2010; 44: 625-632.

5. Adam DJ, Beard JD, Cleveland T, Bell J, Bradbury AW, Forbes JF, et al. Bypass versus angioplasty in severe ischaemia of the leg (BASIL): Multicentre, randomised controlled trial. Lancet 2005; 366: $1925-1934$.

6. Soga Y, Iida O, Kawasaki D, Yamauchi Y, Suzuki K, Hirano K, et al. Contemporary outcomes after endovascular treatment for aorto-iliac artery disease. Circ J 2012; 76: 2697-2704.

7. Tendera M, Aboyans V, Bartelink ML, Baumgartner I, Clément D, Collet JP, et al. ESC Guidelines on the diagnosis and treatment of peripheral artery diseases: Document covering atherosclerotic disease of extracranial carotid and vertebral, mesenteric, renal, upper and lower extremity arteries: The Task Force on the Diagnosis and Treatment of Peripheral Artery Diseases of the European Society of Cardiology (ESC). Eur Heart J 2011; 32: 2851-2906.

8. Rooke TW, Hirsch AT, Misra S, Sidawy AN, Beckman JA, Findeiss LK, et al. 2011 ACCF/AHA focused update of the guideline for the management of patients with peripheral artery disease (updating the 2005 guideline): A report of the American College of Cardiology Foundation/American Heart Association Task Force on Practice Guidelines: Developed in collaboration with the Society for Cardiovascular Angiography and Interventions, Society of Interventional Radiology, Society for Vascular Medicine, and Society for Vascular Surgery. J Vasc Surg 2011; 54: e32-e58.

9. Bradbury AW, Adam DJ, Bell J, Forbes JF, Fowkes FG, Gillespie I, et al; BASIL trial Participants. Bypass versus Angioplasty in Severe Ischaemia of the Leg (BASIL) trial: Analysis of amputation free and overall survival by treatment received. J Vasc Surg 2010; 51: 18S$31 \mathrm{~S}$.

10. Schillinger M, Sabeti S, Loewe C, Dick P, Amighi J, Mlekusch W, et al. Balloon angioplasty versus implantation of nitinol stents in the superficial femoral artery. N Engl J Med 2006; 354: 1879-1888.

11. Laird JR, Katzen BT, Scheinert D, Lammer J, Carpenter J, Buchbinder $\mathrm{M}$, et al. Nitinol stent implantation versus balloon angioplasty for lesions in the superficial femoral artery and proximal popliteal artery: Twelve-month results from the RESILIENT randomized trial. Circ Cardiovasc Interv 2010; 3: 267-276.

12. Suzuki K, Iida O, Soga Y, Hirano K, Inoue N, Uematsu M, et al. Long-term results of the S.M.A.R.T. Control ${ }^{\mathrm{TM}}$ stent for superficial femoral artery lesions, J-SMART registry. Circ J 2011; 75: 939-
944.

13. Iida O, Soga Y, Hirano K, Okamoto S, Dohi T, Uematsu M, et al. Retrospective multicentre analysis of S.M.A.R.T. vs. Luminexx nitinol stent implantation for superficial femoral artery lesions (REAL SL) Registry: 5 years' experience. Circ J 2011; 75: 421-427.

14. Dormandy JA, Rutherford RB. Management of peripheral arterial disease (PAD): TASC Working Group: TransAtlantic Inter-Society Consensus (TASC). J Vasc Surg 2000: 31: S1-S296.

15. Bradbury AW, Adam DJ, Bell J, Forbes JF, Fowkes FG, Gillespie I, et al. Bypass versus Angioplasty in Severe Ischaemia of the Leg (BASIL) trial: An intention-to-treat analysis of amputation-free and overall survival in patients randomized to a bypass surgery-first or a balloon angioplasty-first revascularization strategy. J Vasc Surg 2010; 51: $5 \mathrm{~S}-17 \mathrm{~S}$.

16. Azuma N, Uchida H, Kokubo T, Koya A, Akasaka N, Sasajima T. Factors influencing wound healing of critical ischaemic foot after bypass surgery: Is the angiosome important in selecting bypass target artery? Eur J Vasc Endovasc Surg 2012; 43: 322-328.

17. Forbes JF, Adam DJ, Bell J, Fowkes FG, Gillespie I, Raab GM, et al. Bypass versus Angioplasty in Severe Ischaemia of the Leg (BASIL) trial: Health-related quality of life outcomes, resource utilization, and cost-effectiveness analysis. J Vasc Surg 2010; 51: 43S-51S.

18. Dake MD, Ansel GM, Jaff MR, Ohki T, Saxon RR, Smouse HB, et al. Paclitaxel-eluting stents show superiority to balloon angioplasty and bare metal stents in femoropopliteal disease: Twelve-month Zilver PTX randomized study results. Circ Cardiovasc Interv 2011; 4: 495-504.

19. Karnabatidis D, Spiliopoulos S, Diamantopoulos A, Katsanos K, Kagadis GC, Kakkos S, et al. Primary everolimus-eluting stenting versus balloon angioplasty with bailout bare metal stenting of long infrapopliteal lesions for treatment of critical limb ischemia. $J$ Endovasc Ther 2011; 18: $1-12$.

20. Rastan A, Noory E, Zeller T. Drug-eluting stents for treatment of focal infrapopliteal lesions. Vasa 2012; 41: 90-95.

21. Tepe G, Zeller T, Albrecht T, Heller S, Schwarzwälder U, Beregi JP, et al. Local delivery of paclitaxel to inhibit restenosis during angioplasty of the leg. N Engl J Med 2008; 358: 689-699.

22. Schmidt A, Piorkowski M, Werner M, Ulrich M, Bausback Y, Bräunlich S, et al. First experience with drug-eluting balloons in infrapopliteal arteries: Restenosis rate and clinical outcome. J Am Coll Cardiol 2011; 58: 1105-1109. 